\title{
Challenges in the Diagnosis of Chronic Obstructive Pulmonary Disease
}

\author{
Sean P. O'Reilly
}

Published online: 5 July 2014

(c) Springer Science+Business Media New York 2014

\section{Introduction}

Chronic obstructive pulmonary disease (COPD) is a significant cause of mortality and morbidity worldwide and represents the most common chronic lung disease [1]. Diagnosis of COPD often occurs late in the course of the disease, when symptoms are advanced. Although controversy exists regarding exactly how the course of the disease can be modified, early diagnosis could provide opportunities to modify risk factors such as tobacco use and limit disease progression. Challenges in the diagnosis of COPD will be explored in this article.

\section{Diagnosis of COPD}

Chronic obstructive pulmonary disease (COPD) is a preventable and treatable disease, marked by persistent airflow limitation and chronic lung and systemic inflammation, usually due to exposure to noxious particles or gases, most commonly tobacco smoke and biomass fuels [2••]. The diagnosis should be suspected in patients with cough, sputum production, fatigue, or shortness of breath who have exposure to a known cause, such as tobacco smoke, biomass fuel, or occupational dusts or chemicals. Spirometry is required to confirm the diagnosis, specifically a FEV1/FVC ratio of less than or equal to $70 \%$ which is not reversible. In the earliest phase of disease, patients with COPD often have minimal or no symptoms. Patients

\section{S. P. O'Reilly $(\square)$}

Division of Allergy, Pulmonary, and Critical Care Medicine, University of Massachusetts Medical School, 55 Lake Avenue North, Worcester, MA 01655, USA

e-mail: sean.oreilly@umassmemorial.org readily adapt their lifestyles to offset diminished exercise capacity and rarely seek evaluation early in the disease. Cough, wheezing, sputum production, and shortness of breath are symptoms, which become increasingly more common as spirometric values of lung function decline. However, up to $21 \%$ of patients with severe to very severe airflow limitation by spirometry describe no symptoms [3]. Even when symptoms arise, they are nonspecific, with a recent study showing that even when three or more of the common symptoms of COPD are present, they cannot discriminate between patient with or without airflow obstruction [4•]. Patients can also present with different complaints. Studies have shown that male patients with COPD present more commonly with complaints of cough and phlegm production, whereas female patients often note more dyspnea and decreased quality of life, even with lower pack years of tobacco use and similar lung function $[5,6]$. Gender bias is also a barrier in women to the diagnosis of COPD, as demonstrated by a study where spirometry data improved an inherent gender bias seen when physicians were more likely to diagnose COPD in men than women, when both presented with similar symptoms and clinical characteristics [7, 8].

\section{Spirometry in the Diagnosis of COPD}

Primary care physicians, who see the highest numbers of patients with early COPD, underutilize spirometry to help diagnose COPD [9]. Underutilization of spirometry seems to be a worldwide trend, with spirometry being measured in $36.7 \%$ of US VA patients with a recent diagnosis of COPD, and rates of $59 \%$ in Sweden and $56 \%$ in Canada $[10,11,12 \bullet, 13]$. Spirometry is utilized in higher rates at specialty respiratory medicine clinics, likely related to the 
higher priority placed on spirometry in respiratory illness, available equipment and adequately trained staff, and confidence in the interpretation of the results [14]. Nihilism regarding the utility of spirometry in the management of early-stage COPD and time constraints also lead to reduced use of spirometry in primary care. While current recommendations from the US Preventive Task Force recommend against screening asymptomatic adults for COPD, they do recommend spirometry for adults with respiratory complaints of chronic cough, sputum production, wheezing, and dyspnea [15]. Two common strategies for diagnosing early COPD include case finding, evaluating patients with common COPD symptoms, and screening, evaluating those who are at risk but asymptomatic. COPD has been found to be common in patients who smoke and present to outpatient urgent care centers with symptoms of acute respiratory infection, being found in $27 \%$ overall, of whom $45 \%$ were in GOLD Stage 1 disease [16]. Screening asymptomatic smokers may detect higher numbers of patients with COPD. Comparing symptomatic smokers recruited from the community with evaluation of asymptomatic smokers in a smoking cessation program found a higher prevalence of spirometrically confirmed COPD in those who were asymptomatic 13.3 versus $10.1 \%$, suggesting that screening of all smokers can detect more cases of COPD [17]. Clearly, suspicion of and confirming the diagnosis of COPD in primary and urgent care practices remains important and key to earlier recognition of the disease. In the era of electronic health records and increased availability of administrative and healthcare data, algorithms have been tested to screen for patients at risk of COPD. Mapel et al. have described two algorithms, one consisting of inpatient, outpatient, and pharmacy resource utilization and one consisting simply of pharmacy utilization and have shown to be helpful in identifying patients at risk of COPD. While the more comprehensive algorithm was more sensitive, the pharmacy-based algorithm required less data collection and may be more easily integrated with other methods of identifying those who should be further evaluated for COPD [18, 19].

\section{Challenges to Early Detection of COPD}

Primary care physicians have cited the lack of clear mortality improvement in many COPD patients, the burden of spirometric testing, and time limitations given other coexisting chronic diseases as reasons for not implementing spirometry into their practices [20]. Data on the performance of spirometry in primary care have been mixed with studies demonstrating improved diagnosis and management of COPD, and others showing no utility to spirometry. This was demonstrated in a retrospective review by Walker et al. [21] which showed that patients with moderate to severe COPD were often not on longer-acting bronchodilators, and office spirometry improved management without the need for specialty referrals. However, a large randomized study among Italian primary care physicians showed no utility of adding spirometry to conventional diagnosis of obstructive lung diseases, including COPD [22]. The study was hindered by lack of enrollment of planned subjects and demonstrated that enthusiasm for spirometry in primary care is low and even with intensive education and promotion is difficult to maintain. However, the last study was reassuring that clinical suspicion based on a good history and physical exam is useful and that COPD should be considered in those at risk.

\section{Benefits of Earlier COPD Diagnosis}

The importance of early diagnosis of COPD in altering the course of disease remains controversial. Recent, intriguing evidence showing that the rate of lung function decline is highest in the moderate stages of disease raises hope that earlier accurate diagnosis of COPD, more intense tobacco cessation efforts, and earlier initiation of specific therapies could improve outcomes. In Fletcher and Peto's original work on the natural history of tobacco-related obstructive lung disease, loss of lung function, as measured by $\mathrm{FEV}_{1}$, was originally thought to accelerate over time in patients with COPD [23]. More recent data collected from the placebo arms of pharmacologic trials suggest important differences. Tantucci and Modina [24••] found that the rate of $\mathrm{FEV}_{1}$ decline was highest in patients with GOLD Stage 3 disease and decreased with more advanced disease. Drummond et al. [25••] also looked at predictors of death or rapid lung function decline in the Lung Health Study and found that many smokers with mild to moderate COPD had more rapid decreases in $\mathrm{FEV}_{1}$. In this study, $\mathrm{FEV}_{1} / \mathrm{FVC}$ ratios less than $65 \%$ and lower $\mathrm{FEV}_{1}$ percentages at baseline were associated with accelerated lung function decline, highest in continuing smokers, but also high in intermittent or continuous quitters. Tobacco cessation holds the greatest impact in reducing progressive loss of lung function, and it remains unclear whether earlier diagnosis of COPD leads to higher quit rates. Initial positive results have been found when spirometry is added to brief cessation advice, resulting in a higher quit rate in smokers found to have obstructive lung disease [26]. A lung age, a term developed to help physicians explain spirometry results, has been developed and has shown promise in doubling smoker quit rates, but study methodology has been criticized [27, 28]. Disappointingly, the only randomized, controlled trial of adding spirometry to tobacco counseling showed no benefit [29]. Earlier 
detection of COPD could also get patients onto more effective therapies sooner. This would be hoped to modify the course of the disease, which is determined, by the rate of $\mathrm{FEV}_{1}$ decline and the frequency of exacerbations. Exacerbations clearly affect quality of life, and there is an accelerated decline in $\mathrm{FEV}_{1}$ during these episodes [30, 31]. Certainly patients with frequent exacerbations regardless of absolute $\mathrm{FEV}_{1}$ value and those with symptoms such as dyspnea, which limits their activity, should be considered for maintenance therapy. Currents options for maintenance therapy are increasing but generally include combination inhaled corticosteroids (ICS) and long-acting beta agonists (LABA), LABAs alone, or long-acting muscarinic antagonists alone. Newer combinations of these medication classes are being introduced. Maintenance therapy in patients with moderate COPD, $\mathrm{FEV}_{1} 50-80 \%$ predicted, has been shown to reduce the rate of decline of $\mathrm{FEV}_{1}$ and even mortality. The subset of patients with moderate COPD in the Towards a Revolution in COPD Health (TORCH) study benefitted from the combination of salmeterol/fluticasone and had improved $\mathrm{FEV}_{1}$ values and quality of life, a reduction in the frequency of exacerbations, and even reduced mortality [32, 33]. Trending towards significance, the rate of decline of $\mathrm{FEV}_{1}$ also improved with this combination therapy. Another subset analysis of patients with moderate COPD enrolled in the Understanding Potential Long-Term Impacts on Function with Tiotropium (UPLIFT) demonstrated that this longacting anticholinergic can slow the rate of $\mathrm{FEV}_{1}$ decline, improve quality of life, and reduce exacerbations [34, 35]. A recent intriguing study showed that among smokers found to have rapid $\mathrm{FEV}_{1}$ decline, defined as a drop by $30 \mathrm{ml}$ per year or more, more frequently developed symptomatic COPD during the 3 years follow-up and that the use of angiotensin converting inhibitors (ACE-I) seemed to prevent the FEV1 decline [36•]. The role of initiation of these therapies in mild COPD, $\mathrm{FEV}_{1}$ over $80 \%$ predicted, has not been adequately studied and currently would be limited to those with more frequent exacerbations or had existing dyspnea which impacted their activity level and quality of life.

\section{Harms of Increased Screening for COPD}

Among the goals of the GOLD criteria creation was to simplify the diagnosis of COPD by requiring only an $\mathrm{FEV}_{1} / \mathrm{FVC}$ ratio of less than $70 \%$ after excluding other causes. In doing so, the number of patients with COPD increased two- to threefold [37]. An increase in adverse reactions to medications as well as the high cost to patient and society of the medications themselves would need to be balanced against purported benefits. Presently, to minimize these harms, the diagnosis of COPD should be pursued in only those patients with symptoms of dyspnea, cough, or wheezing, especially those who have exposures to tobacco or other exposures implicated in COPD development. Pharmacologic therapy should be directed at improvement in dyspnea, which detracts from quality of life and those patients with moderate to severe COPD, those with symptomatic dyspnea, and those with frequent exacerbations [38].

\section{Conclusion}

COPD will remain a large-scale public health issue and identifying those at risk and ensuring proper diagnosis is vital. A focused history and physical exam can identify those at risk, and spirometry can be used in select patients to confirm the diagnosis. Future use of electronic medical records and pharmacy records could supplement clinicians' efforts. Interventions and treatment aimed at encouraging and improving tobacco cessation rates remains the single most important factor to modify the course of the disease. While maintenance pharmacologic therapy is usually not indicated in mild COPD, research shows potential benefit in those with moderate disease, although more information is needed regarding long-term outcomes and how these medications influence the course of COPD. If more interventions early in the course of COPD are shown to improve quality of life and reduce mortality and morbidity, many challenges to the diagnosis of COPD can be overcome.

\section{Compliance with Ethics Guidelines}

Conflict of Interest Sean O'Reilly has reported no conflicts of interest.

Human and Animal Rights and Informed Consent This article does not contain any studies with human or animal subjects performed by any of the authors.

\section{References}

Recently published papers of particular interest have been highlighted as:

- Of importance

•- Of major importance

1. Vestbo J, Hurd SS, Agustí AG, et al. Global strategy for the diagnosis, management, and prevention of chronic obstructive pulmonary disease: GOLD executive summary. Am J Respir Crit Care Med. 2013;187(4):347-65.

2. • Global Initiative for Chronic Obstructive Lung Disease. Global strategy for the diagnosis, management, and prevention of chronic obstructive pulmonary disease, NHLBI/WHO workshop 
report. Bethesda: National Heart, Lung, and Blood Institute; 1998. http://www.goldcopd.com. Updated 2013 Sep; Accessed 14 April 2014. Recent update of the GOLD guidelines, a comprehensive guide to al facets of COPD. Increased emphasis on incorporating exacerbation frequency when determining the severity of COPD and when to escalate maintenance therapies.

3. Mannino DM, Gagnon RC, Petty TL, Lydick E. Obstructive lung disease and low lung function in adults in the United States: data from the National Health and Nutrition Examination Survey, 1988-1994. Arch Intern Med. 2000;160:1683-9.

4. - Saad N, Sedeno M, Metz K, Bourbeau J. Early COPD diagnosis in family medicine practice: how to implement spirometry? Int $\mathbf{J}$ Family Med. 2014;2014:962901. doi:10.1155/2014/962901. Study demonstrating that primary care physicians rarely perform office spirometry due to competing medical issues and a perceived lack of utility of spirometry in the diagnosis of COPD.

5. Martinez F, Curtis J, Sciurba F, Mumford J, Giardino N, Weinmann G, Kazerooni E, Murray S, Criner G, Sin D, et al.; NETT Research Group. Sex differences in severe pulmonary emphysema. Am J Respir Crit Care Med 2007;176:243-52.

6. Martinez CH, Raparla S, Plauschinat CA, Giardino ND, Rogers B, Beresford J, Bentkover JD, Schachtner-Appel A, Curtis JL, Martinez FJ, Han MK. Gender differences in symptoms and care delivery for chronic obstructive pulmonary disease. J Women's Health. 2012;21(12):1267-74.

7. Miravitlles M, de la Roza C, Naberan K, Lamban M, Gobartt E, Martin A, Chapman KR. Attitudes toward the diagnosis of chronic obstructive pulmonary disease in primary care. Arch Bronconeumol. 2006;42:3-8.

8. Han MK, Postma D, Mannino DM, Giardino ND, Buist S, Curtis JL, Martinez FJ. Gender and chronic obstructive pulmonary disease: why it matters. Am J Respir Crit Care Med. 2007;176:1179-84.

9. Radin A, Cote C. Primary care of the patient with chronic obstructive pulmonary disease-part 1: frontline prevention and early diagnosis. Am J Med. 2008;121(7):S3-12.

10. Yu WC, Fu SN, Tai EL, Yeung YC, Kwong KC, Chang Y, Tam $\mathrm{CM}$, Yiu YK. Spirometry is underused in the diagnosis and monitoring of patients with chronic obstructive pulmonary disease (COPD). Int J Chronic Obstr Pulm Dis. 2013;8:389-95. doi:10.2147/COPD.S48659.

11. Joo MJ, Lee TA, Weiss KB. Geographic variation of spirometry use in newly diagnosed COPD. Chest. 2008;134:38-45.

12. - Arne M, Lisspers K, Stallberg B, et al. How often is diagnosis of COPD confirmed with spirometry? Respir Med. 2010;104(4):550-6. Study demonstrating poor use of spirometry in confirming COPD.

13. Bourbeau J, Sebaldt RJ, Day A, et al. Practice patterns in the management of chronic obstructive pulmonary disease in primary care practice: the CAGE study. Can Respir J. 2008;15(1):13-9.

14. O'Dowd LC, Fife D, Tenhave T, Panettieri RA., Jr. Attitudes of physicians toward objective measures of airway function in asthma. Am J Med. 2003;114(5):391-396

15. U.S. Preventive Services Task Force. Screening for Chronic Obstructive Pulmonary Disease Using Spirometry: U.S. Preventive Services Task Force Recommendation Statement. Ann Intern Med. 2008;148:529-34.

16. Sandelowsky H, Ställberg B, Nager A, Hasselström J. The prevalence of undiagnosed chronic obstructive pulmonary disease in a primary care population with respiratory tract infections-a case finding study. BMC Fam Pract. 2011;12:122. doi:10.1186/ 1471-2296-12-122.

17. Sansores RH, Ramírez-Venegas A, Hernández-Zenteno R, et al. Prevalence and diagnosis of chronic obstructive pulmonary disease among smokers at risk. A comparative study of case-finding vs. screening strategies. Respir Med. 2013;107(4):580-6. doi:10. 1016/j.rmed.2012.12.010.

18. Mapel DW, Frost FJ, Hurley JS, et al. An algorithm for the identification of undiagnosed COPD cases based on health care utilization data. J Manag Care Pharm. 2006;12(6):457-65.

19. Smidth M, Sokolowski I, Kærsvang L, Vedsted P. Developing an algorithm to identify people with Chronic Obstructive Pulmonary Disease (COPD) using administrative data. BMC Med Inf Decis Mak. 2012;22(12):38.

20. Joo MJ, Sharp LK, Au DH, Lee TA, Fitzgibbon ML. Use of spirometry in the diagnosis of COPD: a qualitative study in primary care. COPD. 2013;10(4):444-9.

21. Walker PP, Mitchell P, Diamantea F, Warburton CJ, Davies L. Effect of primary care spirometry on the diagnosis and management of COPD. ERJ. 2006;28:945-52.

22. Lusuardi M, DeBenedetto F, Paggiaro P, et al. A randomized controlled trial on office spirometry in asthma and COPD in standard general practice. Chest. 2006;129:844-52.

23. Fletcher $\mathrm{C}$, Peto R. The natural history of chronic airflow obstruction. Br Med J. 1977;1(6077):1645-8.

24. •• Tantucci C, Modina D. Lung function decline in COPD. Int J Chronic Obstr Pulmon Dis. 2012;7:95-9. Study demonstrating that more rapid decline in FEV $V_{1}$ may occur in the moderate stages of COPD compared to the severe stage, possibly identifying new optimism about earlier initiation of disease modifying interventions.

25. •- Drummond MB, Hansel NN, Connett JE, Scanlon PD, Tashkin DP, Wise RA. Spirometric predictors of lung function decline and mortality in early chronic obstructive pulmonary disease. Am J Respir Crit Care Med. 2012;185(12):1301-6. Study demonstrating that rapid lung function declines in the moderate stage of COPD, again raising possibility disease progression should be addressed earlier in the course of COPD.

26. Bednarek M, Gorecka D, Wielgomas J, Czajkowska-Malinowska M, Regula J, Mieszko-Filipczyk G, et al. Smokers with airway obstruction are more likely to quit smoking. Thorax. 2006;61:869-73.

27. Morris JF, Temple W. Spirometric, "lung age" estimation for motivating smoking cessation. Prev Med. 1985;14(5):655-62.

28. Parkes G, Greenhalgh T, Griffin M, Dent R. Effect on smoking quit rate telling patients their lung age: the Step2quit randomized controlled trial. BMJ. 2008;336(7644):598-600.

29. Kotz D, Wesseling G, Huibers MJ, van Schayck OC. Efficacy of confronting smokers with airflow limitation for smoking cessation. Eur Respir J. 2009;33(4):754-62.

30. Kanner RE, Anthonisen NR, Connett JE, Lung Health Study Research Group. Lower respiratory illnesses promote FEV1 decline in current smokers but not ex-smokers with mild chronic obstructive pulmonary disease. Am J Respir Crit Care Med. 2001;164(3):358-64.

31. Donaldson GC, Seemungal TAR, Bhowmik A, Wedzicha JA. Relationship between exacerbation frequency and lung function decline in chronic obstructive pulmonary disease. Thorax. 2002;57(10):847-52.

32. Jenkins C, Jones P, Calverley P, Celli B, Anderson J, Ferguson G, et al. Efficacy of salmeterol/fluticasone propionate by GOLD stage of chronic obstructive pulmonary disease: analysis from the randomised, placebo-controlled TORCH study. Respir Res. 2009;10:59.

33. Celli BR, Thomas NE, Anderson JA, Ferguson GT, Jenkins CR, Jones PW, et al. Effect of pharmacotherapy on rate of decline of lung function in chronic obstructive pulmonary disease: results from the TORCH study. Am J Respir Crit Care Med. $2008 ; 178: 332-8$. 
34. Decramer M, Celli B, Kesten S, Lystig T, Mehra S, Tashkin DP. Effect of tiotropium on outcomes in patients with moderate chronic obstructive pulmonary disease (UPLIFT): a prespecified subgroup analysis of a randomised controlled trial. Lancet. 2009;374:1171-8.

35. Tashkin DP, Celli B, Senn S, Burkhart D, Kesten S, Menjoge S, et al. A 4-year trial of tiotropium in chronic obstructive pulmonary disease. N Engl J Med. 2008;359:1543-54.

36. • Petersen H, Sood A, Meek PM, et al. Rapid lung function decline in smokers is a risk factor for COPD and is attenuated by angiotensinconverting enzyme inhibitor use. Chest. 2014;145(4):695-703.
Intriguing retrospective study examining the rate of $F E V_{1}$ decline and the development of COPD and possible utility of ACE inhibitors in modifying the course of $C O P D$.

37. Enright P. Does screening for COPD by primary care physicians have the potential to cause more harm than good? Chest. 2006;129(4):833-5.

38. Wilt TJ, Niewoehner D, Kim C, for the Agency for Healthcare Research and Quality (AHRQ), et al. Use of spirometry for case finding, diagnosis, and management of COPD. AHRQ Publication No. 05-E017-1. Rockville: Agency for Healthcare Quality and Research; 2005. 